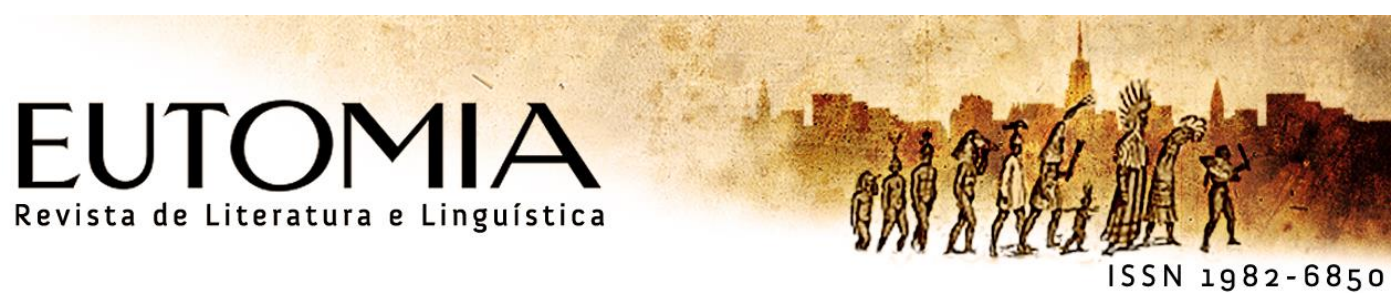

\title{
Formação docente inicial e continuada: entre avaliação do agir e configuração de saberes
}

\author{
Lídia Stutzi (UNICENTRO)
}

Fábio Delano Vidal Carneiroii (Faculdade Sete de Setembro)

\begin{abstract}
Resumo: Objetiva-se investigar a reflexão que o professor de línguas faz da sua ação docente e a relação dessa reflexão com o desenvolvimento dos saberes necessários ao seu trabalho. Para tanto, foram utilizadas as figuras do agir advindas do construto teórico-metodológico do interacionismo sociodiscursivo (BRONCKART, 2004; BULEA, 2010) e os saberes docentes (HOFSTETTER; SCHNEUWLY, 2009; EUROPA, 2007) para dar suporte às análises. A geração dos dados provém de dois instrumentos: a) socialização de diários de professores em formação inicial (estágio supervisionado) em uma universidade do sul do Brasil,e b) entrevistas realizadas antes e depois de aulas de língua materna em escolas públicas municipais na região Nordeste. Em ambas as situações de pesquisa, os resultados apontam a bifurcação da rede de interpretações gerada pelos professores, ora se referindo ao próprio agir (figuração do agir interno), ora se referindo ao agir dos alunos (figuração do agir externo), ensejando uma dupla ancoragem tanto do ponto de vista ontológico (a ação é realizada pelo professor, mas sempre com uma expectativa sobre o agir do aluno), quanto gnosiológico (a interpretação do agir referente ocorre por meio de figuras de ação internas e externas). Essa característica distingue o professor de outros profissionais cuja figuração do agir se restringe quase totalmente ao seu agir. Os saberes subjacentes evidenciados centram-se em saberes sobre os recursos,acerca de avaliação das capacidades de linguagem dos alunos, a respeito do conteúdo e concermente ás estratégias de ensino-aprendizagem em sala de aula, revelando a coerência entre o duplo viés gnosiológico da reflexão do professor e os saberes mobilizados na sua prática.
\end{abstract}

Palavras-chave: Saberes Docentes, Figuras de Ação e Professores de Línguas em Formação Inicial e Continuada

Abstract: This study aims at investigating language teacher's reflection about the teaching action and its relation with the development of knowledge concerned to his/her work. Therefore, we used action figures based on the framework of sociodiscursive interactionism (BRONCKART, 2004b; BULEA, 2010) and teaching knowledge (HOFSTETTER; SCHNEUWLY, 2009; EUROPA, 2007) to support our analysis. The generation of the data comes from two tools: a)pre-service teachers diary socialization produced during supervised training at a university in southern Brazil and b) interviews produced before and after first language classes in public schools in the Northeast region. In both research situations, the results show a bifurcation of the network interpretations generated by teachers, alternating the reference to his/her own act (internal action figure), or to the act of 
students (external action figure), generating a double anchoring of the ontological point of view (the action is carried out by the teacher, but always with an expectation on the action of the student), and of the gnosiological point of view (the interpretation of the referent-action occurs through internal and external action figures). This characteristic distinguishes the teacher from other professionals which action figures are limited almost always to its own action. The evidenced underlying knowledge points out to knowledge about the resources, about assessment of pupils' language capacities, about the content and the strategies of teaching and learning in the classroom, revealing the coherence between the double gnosiological bias of teacher reflection and the types of knowledge mobilized in their practice.

Keywords: teaching knowledge, action figures, pre- and in-service language teachers

\section{Introdução}

Este trabalho tem como objetivo investigar a reflexão que o professor de línguas faz da sua ação docente e a relação dessa reflexão com o desenvolvimento dos saberes necessários ao seu trabalho. É essa reflexão, urdida na prática e materializada em texto (entrevistas, diários de classe, relatos escritos ou orais etc), que consideramos a sede gnosiológica dos saberes e capacidades docentes. Na concepção do Interacionismo Sociodiscursivo, o desenvolvimento humano (tanto individual quanto coletivo) acontece na interação mediada linguageiramente. Consequentemente, se pretendemos observar cientificamente os saberes e capacidades necessários ao trabalho docente, devemos iniciar essa observação com suporte na análise que o professor faz da sua prática.

A formação dos profissionais instaura-se verdadeiramente (isto é, em forma de práxis), na medida em que estes são capazes de refletir sobre a sua prática, transformando o agir em ação relatada e avaliada. Assim, é por meio da ação de reformulação do professor que são sedimentados conjuntos de representações acerca do seu ofício. O que o professor pensa que sabe? Como ele avalia sua ação e a ação dos demais actantes, copartícipes do agir educacional? De que maneira o profissional acumula, prioriza e assume determinados saberes como recursos para sua conduta, ou seja,como experiência valorada? Essas perguntas estão no centro da discussão da relação entre a prática e a formação profissionais.

Na qualidade de profissional (ator de uma situação de trabalho), o professor, por exemplo, traz a cena um agir (ação + reflexão sobre a ação) prévio, proveniente da junção de experiências e conhecimentos anteriores. Essa colocação em cena entretanto, não é mera ativação de esquemas, mas uma real reconstituição gnosiológica. Em outros termos, 
as representações objetivadas, ao serem confrontadas com novos contextos, são objetos de reformulação mediada pela linguagem.

Do ponto de vista longitudinal, o desenvolvimento dos saberes e capacidades docentes perpassa os contextos formativos iniciais, de um lado, e continuados, de outro. $\mathrm{O}$ profissional está sempre em formação. Desde o início dessa formação (antes mesmo da formação inicial, na qualidade de aluno), e por todo o seu percurso agentivo/docente, o professor reformula seus conhecimentos a ensinar e suas capacidades para ensinar. Nessa dinâmica formativa, encontramos o sucesso ou fracasso da ação docente. Sem dúvidas, o trabalho do professor é em muito dependente das condições de trabalho, das políticas escolares e do entorno social de seus alunos. Esse trabalho, entretanto, encontra muito mais dificuldade quando falta a esse professor uma formação teórica e prática fundamentada na reflexão (SCHON, 1983; BRONCKART, 2004).

A formação inicial e continuada sem os saberes necessários para conduzir as práticas didáticas enseja o esvaziamento do trabalho docente $(\mathrm{FACCl}, 2011)$ e torna o professor um mero executor, que não provê (trans)formações no meio onde atua por carecer de capacidades docentes. Os saberes docentes, de modo geral, partem de representações de ordem praxiológica, epistemiológica e ética. Nessa linha de pensamento, para alcançar resultados transformadores, prepondera a necessidade de articular esses saberes para contribuir nas dimensões citadas: "o que faço com o que sei (praxiologia); quais as minhas possibilidades de saber (epistemologia) e qual a justeza do que sei (ética)" (CARNEIRO, 2014, p. 78). Então, observamos que há especificidades a serem compreendidas e, para tanto, lançamos o questionamento: quais são os saberes necessários para a formação que possam munir o professor e torná-lo em real responsável pelo trabalho docente?

Considerando nossa preocupação na formação inicial e continuada trazemos duas análises do discurso do professor de línguas sobre o seu agir. Inserimos neste artigo algumas situações referentes à reflexividade de professores para adentrar as especificidades do trabalho e formação dos docentes de línguas com base em dois contextos: um da região Sul com alunos-professores de Língua inglesa, de uma universidade pública ao participarem das aulas de estágio supervisionado, e outro de professores de Língua Portuguesa (LM) da região Nordeste em escolas municipais públicas. 
No primeiro contexto, os dados provêm da socialização de diários, instrumento utilizado para compreender as avaliações e possíveis tensões dos alunos-professores ao se engajarem nas atividades da docência. A socialização dos diários consiste no compartilhamento de relatos e narrativas entre os futuros professores e professor formador, no intuito de promover reflexão e ressignificação sobre as experiências advindas da prática (STUTZ, 2012). A prática de elaborar relatos interativos na formação inicial ancora-se em pesquisadores diversos, entre eles Machado (1998) e Reichmann (2012).

Já no segundo contexto, os dados foram gerados de entrevistas gravadas imediatamente antes e depois de aulas de Língua Portuguesa para alunos dos $2^{\circ}, 5^{\circ}, 6^{\circ}$ e $9^{\circ}$ anos do ensino fundamental. A gravação de entrevistas e sua posterior transcrição e análise são aqui concebidas como produção dialógica com base na condução dos questionamentos. Neste caso, foram realizadas perguntas que incitavam o professor a deslindar uma visão prospectiva (o que ele havia planejado para a aula, quando da entrevista antes da aula, e uma visão retrospectiva/avaliativa (o que realmente aconteceu na aula e como ele avalia o que ocorreu). Esta investigação foi inspirada particularmente na pesquisa de Bulea (2007) e de outros (EMPEYTA, 2010; PEIXOTO, 2012; FRANCINETTI, 2013; LEURQUIN, 2014), que buscam investigar a figuração do agir profissional. Nossa pesquisa se concentra entretanto no agir-referente: sala de aula de língua materna.

Assim, este estudo visa a analisar agires e saberes subjacentes à reflexividade de (futuros) docentes de línguas. O artigo está configurado da seguinte forma: primeiramente, indicamos brevemente a revisão da literatura que direciona as nossas análises para a concepção do ISD sobre a linguagem e as figuras do agir, e a formação docente sob o viés dos saberes docentes; na sequência, discorremos sobre o itinerário da pesquisa na seção da metodologia; na terceira parte, debruçamo-nos sobre as análises com base em excertos selecionados dos dois contextos; e, por fim, trazemos as considerações finais.

\section{Entre avaliação do agir e configuração de saberes}

\subsection{Linguagem e figuração do agir}

Os trabalhos realizados no quadro do Interacionismo Sociodiscursivo (BRONCKART, 1997; BULEA, LEUROUIN; CARNEIRO, 2013) indica que as escolhas discursivas, operadas pelos ators no quadro dos diversos gêneros orais e escritos - a propósito do seu trabalho - 
se organizam em configurações interpretativas específicas ou "figuras de ação" (BULEA, 2010). Assumem, também, que essas configurações possuem dimensão potencialmente promotora do desenvolvimento, na medida em que elas são a manifestação de um debate relativo ao agir (BULEA, 2007) explorável do ponto de vista formativo.

O ISD, como abordagem monista de fenômenos linguageiros, tece relações com os aportes: a) de Sausurre, acerca da arbritrariedade radical do signo e da dinâmica essencialmente social e histórica dos fatos linguageiros; b) de Vygotsky, no que tange ao postulado de que a linguagem é a verdadeira organizadora do pensamento, ao mesmo tempo em que permite as ações e interações propriamente humanas, i.e., autoconscientes; e c) de Voloshinov, nos termos em que defende a dialogicidade como princípio fundador de todo enunciado. Dessa forma, na e pela práxis de atividades de linguagem (mediadoras de todas as demais atividades humanas) se produz a dinâmica das interações dos mundos coletivos da cultura e os mundos individuais de conhecimentos (BRONCKART, 2006).

A primeira consequência dessa visão sobre a linguagem é a de fazer (re)pensar o papel da linguagem na tomada de consciência do profissional sobre si e a respeito do próprio agir, dando-Ihe condições de redimensionar sua prática. O ISD faz, portanto, um de seus objetos a análise das avaliações linguageiras dos profissionais acerca do seu agir.

As escolhas discursivas dos professores relativamente à interpretação do seu agir e os "efeitos" dessa interpretação sobre a elaboração de variados aspectos do trabalho educacional (identidades, saberes específicos, interpretação do prescrito etc.), além da possível exploração para fins formativos são, portanto, a categoria de análise referenciadora que denominaremos de figuração do agir. O agir profissional é representado com amparo em interpretações temático-discursivas apreensíveis desde os textos/discursos produzidos pelos próprios profissionais acerca da sua atividade (FIGURAS DE AÇÃO). BRONCKART (2004.a) exprime as distintas interpretações como estratégias de reorganização das autorepresentações profissionais, cuja atualização constante serve de "motor de desenvolvimento" das pessoas em situação de trabalho.

Bulea $(2007,2010)$ em pesquisas sobre o agir de várias profissões identificou cinco modalidades de figuras de ação com suporte em textos orais (entrevistas). 
Quadro 1. Figuras do agir

Ação Ocorrência É um relato ocorrido durante a aula, mas por demais ligado ao contexto de produção, isto é, que não revela nenhuma generalização quanto ao agir profissional do professor.

Ação acontecimento passado É o correspondente da ação ocorrência, quando o professor se refere a algum acontecimento realizado em um evento anterior ao que está sendo descrito e é usado para contextualizar uma ocorrência dentro de um período maior. Também é evocada antes de uma conclusão (ação experiência) para dar-Ihe maior legitimidade.

Ação Experiência Também da ordem do relato, mas com uma forte tendência a se destacar do contexto de produção e a assumir o estatuto de repertório profissional daquele como professor. Em outras palavras, é um relato que expressa uma conclusão acerca de algum modo de fazer o ensino ou de ser professor.

Ação Canônica É um recorte teórico advindo de acordos ou prescrições prévias à realização da tarefa de ensinar. Podem ser regras da própria escola, da secretaria de ensino, combinados da equipe de professores etc.

Ação Definição A figura da ação definição recobra uma compreensão do agir como "fenômeno no mundo", convidando a uma reflexão em termos de redefinição, explicitação do que ele é. Ela está inserida em segmentos relevantes do discurso teórico, mas, contrariamente à ação canônica, as formas verbais mobilizadas só tratam, raramente, de atos ou gestos: a maioria das relações predicativas é constituída das construções impessoais.

Fonte: quadro elaborado pelos autores com base em Bulea (2010).

Nessa complexa figuração do agir, ou seja, na reflexão epistemologicamente recortada, o ator avalia o que fez, já escolhendo, ante a amplitude do seu agir, aquilo que considera mais importante, essencial. Na verdade, é um duplo julgamento com distintos graus de consciência ou de intencionalidade.

As práticas humanas são entretanto essencialmente coletivas. São organizadas por meio de acordos, normas, modos de fazer em que vários actantes colaboram, inclusive com a mediação essencial da linguagem, sem falar na articulação entre as várias práticas sociais. Dessa forma, também encontramos a figuração do agir desse(s) outro(s) actante(s) no discurso do ator que relata/avalia o seu agir. Em suma, as figuras de ação que descrevemos anteriormente se repetem, nas suas características linguístico-discursivas e temáticas, em figuras de ação EXTERNA.

Para este estudo, é importante apontar que as pesquisas em torno do agir do professor (BULEA, 2010; EMPEYTA: 2010; PEIXOTO: 2012; FRANCINETTI, 2013; LEURQUIN: 2014) revelam que este profissional recorre com uma frequência muito grande (de $40 \%$ a $60 \%$ das proposições dos textos produzidos) a uma análise do agir dos alunos. 
Isso denota que o agir dos alunos é, na perspectiva do professor, um critério de avaliação crucial imbricado sobre o seu agir.

Essa característica do professor denota uma reverberação nos saberes mobilizados na execução do seu trabalho. Debruçamo-nos, a seguir, sobre a questão dos saberes para enfim relatarmos as pesquisas realizadas e seus resultados.

\subsection{Formação docente e saberes e capacidades docentes}

No Brasil, os documentos oficiais prescrevem três eixos norteadores da formação de professores: as competências docentes, a pesquisa e a coerência entre a formação oferecida e prática esperada (BRASIL, 2001). Apoiamo-nos dois últimos eixos por considerarmos que a pesquisa sobre a própria prática envolve reflexividade e enseja agires mais autônomos ao professor. Da mesma forma, a necessidade de atrelar teoria e prática conduz para práticas coerentes e a aprendizagens mais significativas dos alunos. Refutamos no entanto ,o termo competências por estar atrelado a valores mercadológicos e que concebem a docência como mera execução de tarefas, distanciando o professor do seu papel de ator responsável pela ação (BRONCKART, 2006; MACHADO; CRISTOVÃO, 2005).

Sob os aportes do ISD, emprestamos a noção de saberes de Schneuwly (2008, p. 64) que os concebe como "conjuntos de enunciados ou de procedimentos sistematicamente elaborados, incorporados nas práticas discursivas circunscritas, constituídas e reconhecidas socialmente". Os saberes organizam-se em sistemas complexos, sendo que as apropriações longas e sistemáticas ensejam transformações profundas na forma de pensar, agir e utilizar a língua (SCHNEUWLY, 2010). A apreensão de novos saberes propicia novas possibilidades de agir em distintas esferas e, portanto, é crucial para a formação de professores.

A formação de professores, conforme Bronckart (2011), Bulea e Bronckart (2010) ancora-se em dois grandes grupos de saberes, os saberes praxiológicos e os saberes epistêmicos. Os primeiros visam a apreender as capacidades da intervenção docente, que, de acordo com Bronckart (2011, p. 10 $10^{1}$ ) se dividem em:

\footnotetext{
${ }^{1}$ Capacidade de "retomar" os objetos teóricos nos objetos de ensino da forma como eles circulam na sala de aula, ou, ainda, de poder tecer relações entre objetos prescritos e objetos realmente ensinados; - a capacidade de identificar os obstáculos que se apresentam durante a realização de um projeto de ensino, obstáculos quanto às resistências dos alunos, às condições de funcionamento da sala de aula, ou ainda, aos fatores socioculturais mas gerais; - a capacidade de identificar as técnicas, truques ou habilidades que os próprios professores utilizam para superar obstáculos (BRONCKART, 2011, p. 10; tradução nossa).
} 
[...]la capacité de "retrouver" les objets théoriques dans les objets d'enseignement tels qu'ils circulent en classe, ou encore de pouvoir mettre en correspondance objets prescrits et objets réellement enseigné;_la capacité d'identifier les obstacles qui se présentent Lors de la réalisation d'un projet d'enseignement, obstacles tenant Aux résistances des éléves, aux conditions de fonctionnement de la classe,ou encore á des facteurs socioculturels plus généraux;_la capacité d'identifier les techniques, ruses ou habilités que les enseignants euxmêmes mettent en oeuvre parfois pour surmonter les obstacles.

Já, com relação aos saberes epistêmicos, os objetivos se voltam para o domínio teórico das noções e regras mobilizadas nos programas, que se tornam essenciais, visto que na ausência real de compreensão dessas noções, os mencionados autores salientam haver uma tendência em gerar abordagens metodológicas dedutivas e autoritárias.

Conforme Hofstetter e Schneuwly (2009), a aprendizagem na escola tradicional tem um fim nela mesma para a formação de uma cultura geral. Os conteúdos ensinados resultam de um complexo de transformações de saberes, que descrevem pontos de vista diferentes, teorias de transposição didática ou da cultura escolar. Os conteúdos do currículo são dispostos de forma a suprir as finalidades da escola e diferenciam-se da aprendizagem cotidiana. Os conteúdos são as aquisições culturais da sociedade para disciplinar e elaborar modos de pensar, falare agir.

Portanto, os autores concentram a investigação no conteúdo - nos saberes formalizados. Eles categorizam o saber como objeto de trabalho atribuído às profissões de ensino e da formação, para reconhecer características constitutivas das instituições nas quais trabalham os profissionais por meio das funções e atividades destinadas a eles. Para os autores, a avaliação de critérios de saberes acadêmicos úteis no ensino sinaliza os mecanismos do trabalho na elaboração dos saberes, mas não oferece evidências da lógica interna, didática constituida em grande parte também sobre a solidarização dos conteúdos. Esses motivos conduzem a categorizar os saberes nas categorias delineadas na sequência.

a) Saberes a ensinar - são os saberes utilizados como objeto de trabalho do professor para ensinar. O professor forma o aluno, ensinando-lhe saberes. "A transformação de saberes em saberes a ensinar" é um processo que modifica "o saber para torná-lo ensinável" (HOFSTETTER; SCHNEUWLY, 2009, p. 18). Para os autores, são os saberes do plano de estudos, do livro didático, que constituem o trabalho do professor. No ensino específico da linguagem, os saberes a ensinar privilegiam os saberes específicos da 
língua (L1 e/ou LE) e estão imbricados nos saberes interdisciplinares relacionados às temáticas abordadas no material linguístico apresentado nas aulas.

b) Saberes para ensinar - são aqueles que constituem o instrumento de trabalho do professor. São os saberes sobre o objeto de trabalho de ensino ou de formação (saberes sobre o aluno, os conhecimentos e seu desenvolvimento, as maneiras de aprender), acerca das práticas de ensino (métodos, abordagens, dispositivos, fragmentações de saberes a ensinar, modalidades de organização e de gestão) e a respeito da instituição que define seu campo de atividade profissional (planos de estudos, instruções, finalidades, estruturas administrativas e políticas) (HOFSTETTER; SCHNEUWLY, 2009).

Em razão dos saberes expostos e das relações tecidas com os saberes epistemológicos e praxiológicos, conforme vimos, frisamos que há um rol de saberes considerados cruciais para a formação de professores. As pesquisas, de modo geral, exprimem esses saberes como transversais e que, portanto, perpassam todas as disciplinas, mas não se atêm às especificidades de cada uma delas. Compreendemos que a formação inicial e continuada do professor de línguas, ao atrelar um determinado rol de saberes „precisa aliá-los às especificidades dos conteúdos a serem ensinados. Por isso, com base nos referidos autores e no Portfólio Europeu de Formação de Professores de Línguas (EUROPA, 2007) e nas adaptações propostos em Stutz (2012), consideramos que um caminho é a imbricação desses saberes conforme quadro a seguir.

Quadro2. Saberes docentes

\begin{tabular}{|c|}
\hline SABERES A ENSINAR \\
o conteúdo, \\
o contexto, \\
o papel do professor, \\
a metodologia, \\
os recursos, \\
a planificação de aulas, \\
a regência de aulas, \\
a aprendizagem autônoma \\
a avaliação da aprendizagem. \\
SABERES PARA ENSINAR
\end{tabular}

Fonte: elaborado pelos autores com base em STUTZ (2012)

O quadro exprime saberes múltiplos sobre o contexto, o papel do professor, as metodologias, recursos didáticos, a maneira de planificar as aulas, a regência de classe, a 
aprendizagem autônoma dos alunos e a avaliação da aprendizagem. Consideramos que o desenvolvimento efetivo dos (futuros)professores envolve a imbricação desses saberes epistemológicos e praxiológicos, que, por sua vez, precisam estar atrelados aos conteúdos das disciplinas a serem ensinadas. Isto porque, ao se imbricar nas disciplinas terão as especialidades e as necessidades que envolvem os saberes a ensinar. Destacamos, assim, que os "saberes para ensinar" se fundem aos "saberes a ensinar" para tratar de elementos e capacidades específicas das disciplinas e das questões gerais da docência. Para cada um dos saberes expostos no quadro, há um rol de capacidades docentes ${ }^{2}$. Exemplificamos aqui um dos saberes - o do conteúdo, que parte dos níveis interno e externo da transposicão didática e envolve capacidades docentes tais quais: capacidade de selecionar o conteúdo que sempre parte de um gênero textual de circulação social, capacidade de compreender as dimensões ensináveis com base em um modelo didático sobre o gênero, capacidade de transpor esse conteúdo para ser didatizado na constituição da sequência didática.

Após a apresentação de nossa ancoragem teórica, seguimos para a próxima seção com o percurso da metodologia.

\section{Metodologia da pesquisa}

Este estudo parte de dois contextos educacionais e instrumentos de geração de dados distintos, conforme apontamos a seguir.

O primeiro contexto compreende a formação inicial de professores de Língua Inglesa. O recorte que utilizamos emana da participação de uma aluna-professora do curso de Letras Inglês de uma universidade pública da região centro sul do Estado do Paraná. A participante foi escolhida por ter o estágio como a primeira experiência de ensino na educação básica (ensino fundamental e médio) e foi ficticiamente nomeada de Anny. A geração dos dados da socialização dos diários foi utilizada para prover momentos de reflexão sobre o trabalho docente no coletivo da turma de quarto ano, na disciplina de Estágio Supervisionado. As sessões de socialização foram realizadas durante todo o ano letivo. De posse do consentimento de todos os participantes, as socializações foram gravadas e transcritas.

$2 \quad$ Ver rol de capacidades docentes em Stutz (2012) 
$\mathrm{Na}$ segunda pesquisa, foram analisados dados empíricos orais, emanados de entrevistas gravadas imediatamente antes e depois de aulas de Língua Portuguesa para alunos dos $2^{\circ}, 5^{\circ}, 6^{\circ}$ e $9^{\circ}$ anos do ensino fundamental. Todos os professores tinham de $10 \mathrm{a}$ 12 anos de experiência profissional e mais de cinco anos de trabalho na rede pública municipal de Fortaleza.

Nos textos-fontes produzidos pelos docentes e analisados nas duas pesquisas, são priorizados os segmentos de texto referentes ao agir-referente, isto é, ao que aconteceu ou acontece em sala de aula, aqui denominados STT (Sequências de Tratamento Temático) ao contrário dos SOTs (Segmentos de Orientação Temática) que são trechos relacionados à entrevista em si, ou a outros assuntos que não guardam relação com o agir-referente.

Como acentua Bronckart (1999), a reflexão sobre as operações enunciativas nos textos e nos gêneros de texto são relevantes, sobremaneira, para a clarificação dos mecanismos constitutivos da atividade linguageira humana, principalmente no que diz respeito à adoção/adaptação de um determinado gênero e sua subsequente consubstanciação em texto empírico:

Tratando-se da análise da arquitetura interna dos textos, será necessário refinar a descrição e a conceitualização dos mecanismos de textualização (de coesão e de conexão em particular) e, sobretudo, obter uma abordagem dos mecanismos enunciativos que mostre melhor o seu caráter decisivo ou que seja mais claramente articulada à análise dos processos constitutivos dos mundos discursivos. (BRONCKART, 1999, p. 339, GRIFO NOSSO)

No caso das entrevistas, procuramos investigar os ângulos de ataques temáticos, os tipos de discurso, a ligação com o contexto de produção, assim como as modalizações e vozes, constitutivas da enunciação, isto é, da dimensão textual em que o autor do texto procura "guiar" o seu leitor de forma a compreender seu posicionamento discursivo, mais ou menos modalizado, ancorado ou não em uma voz individual, social ou neutra, que legitima externa ou internamente os sentidos criados no discurso. 


\section{Análise dos dados}

Procedemos aqui, primeiramente, a uma análise com base em um excerto advindo de uma sessão de socialização de dários, realizada após o período de regência de Estágio Supervisionado. Durante o estágio, a aluna-professora direciona a reflexão para a heterogeneidade dos alunos, quando da realização das práticas em sala de aula. Anny explicita a dificuldade em trazer atividades coerentes com o nível dos estudantes na sequência didática constituída juntamente com outra aluna-professora.

Excerto 1:

Anny: [...] no caso meu pelo menos ....é muito difícil de saber do aluno... as vezes você colocava uma atividade fácil... parece que era muito fácil ... faziam assim ... (torce o nariz) não participavam ... isso quer dizer que está muito fácil ...

[...] Anny: ai que bobeira né ... aí você coloca outra atividade de um grau de dificuldade maior .... [...]

Anny: não fazem ... fiquei ... eu quase chorei assim na prova de desgosto assim de ver

(Socialização de diários 6 - Dia 16 de setembro de 2008.)

Compreendemos que o segmento se caracteriza como ação-acontecimento passado, no qual o desnível da turma causa a tensão pragmática, sendo que as verbalizações revelam a angústia em utilizar as tarefas planejadas na sequência didática. $A$ voz profissional se funde com a da personagem professora e tambem responsável pela elaboração da sequência de atividades. A implicação de Anny "no caso meu", "fiquei ... eu", "chorei" é utilizada para expressar de modo subjetivo por meio de verbos de estado as emoções com que a aluna-professora deparou, quando observou as reações de pouca participação dos alunos na resolução das atividades da sequência didática. A tensão afetiva revela a preocupação com a coerência das tarefas e a responsividade dos alunos. A angústia da aluna-professora é marcada pela avaliação negativa das modalizações apreciativas "muito difícil saber", "ai que bobeira" e "eu quase chorei".

Além da disparidade de conhecimentos dos alunos do terceiro ano do ensino médio - apontamos para uma lacuna, a necessidade de maior precisão dos diagnósticos realizados durante a fase da observação participativa. A situação expressa ecoa com vozes cristalizadas na sócio-história da comunidade educacional, considerando o pequeno engajamento dos alunos e as condições de ensino de Inglês na escola pública. Entra em 
cena "uma conjuntura educacional pouco favorável ao desenvolvimento pleno de um processo de ensino/aprendizagem dos conteúdos da língua inglesa em sala de aula" (SALES; LIMA, 2007, p. 9). As asserções de Anny dão indícios das dificuldades e desafios da escola pública. Se, por um lado, as participações dos alunos estão relacionadas à apropriação dos conhecimentos de Língua Inglesa, de outra parte, a heterogeneidade dificulta a planificação de tarefas.

Com origem nessas análises, as figuras de ação interna (trechos sublinhados) estão aliadas à tensão afetiva da aluna-professora que se implica subjetivamente no trabalho. Ao se reportar aos resultados " fiquei ... eu quase chorei ", mostra que as expectativas não foram alcançadas. A imbricação da figura do agir interno está imbricada na figura do agir externo (trechos em negrito), visto que as expectativas provêm do agir externo, ou seja, das ações dos alunos, conforme explicitam os termos, "do aluno" e "não fazem".

Sob o viés dos saberes e capacidades docentes, constatamos, assim, que as considerações feitas sobre a relação atividade e resposta dos alunos convergem com saberes múltiplos, entre os quais destacamos os saberes quanto aos recursos utilizados, saberes sobre a avaliação, acerca do conteúdo e a respeito da prática em sala de aula. Dessa forma, temos condições de verificar que a aluna-professora evidencia capacidades de analisar as atividades utilizadas, dado o instrumento de interação sequência didática. A aluna-professora analisa a apropriação das atividades da sequência didática e as capacidades dos alunos. Também fica explícito que as reflexões de Anny envolvem a preocupação e a capacidade de analisar a prática que estava desenvolvendo, para examinar se há coerência com as necessidades dos alunos e com as expectativas da escola. Nesse sentido, não podemos deixar de apontar o fato de que a relação da teoria com a prática está imbricada na reflexividade. A avaliação das situações concretas revela a capacidade de atribuir significação às situações para guiar as ações a serem realizadas (VANHULLE, 2005).

A principal característica observada nos dados analisados foi ocomércio simultânea e inter-relacionada do que denominaremos de figuras de ação interna, nas quais o professor reflete, interpreta e elabora linguageiramente componentes do próprio agir, situando-se como a fonte das representações sobre a parte ou as dimensões deste agir que ele se atribui; e figuras de ação externa, nas quais o professor reflete, interpreta e elabora linguageiramente $\mathrm{o}$ agir dos outros protagonistas (aluno, alunos, outros professores). Nestas figuras, a reflexão sempre é feita pelo profissional, que ainda é a fonte das 
representações textualizadas, mas estas representações dizem respeito às porções ou às dimensões do agir realizado por outros protagonistas e não por ele mesmo. Chamamos a atenção para o fato de que não se trata de <<um outro〉> qualquer, mas de co-actantes, isto é, de alguém implicado no agir-referente, seja pela existencia física-temporal, seja pela função social que ocupa. Esta distinção entre figuras de ação internas e externas reexplora e fortalece a distinção genérica feita por Bronckart entre «figura de ação interna» e «figura de ação interna» (ver BRONCKART, 2001). De acordo com o autor, a figura de ação interna procede das representações e avaliações que uma pessoa tem de sua responsabilidade na atividade coletiva, comportando assim componentes (intenções, capacidades, etc.) autorrepresentados, enquanto a figura de ação interna diz respeito às representações e avaliações acerca de ações vindas do exterior, ou produzidas por outros, sob a responsabilidade de uma pessoa ou do coletivo.

O segundo excerto provém do contexto de formação contínua de professores de LM. As análises realizadas nesse contexto apontam que, em $23 \%$ das proposições produzidas pelo professor, encontramos o fenômeno que chamamos de ação experiência interna e externa em conjunção, isto é, implicadas em alternância no discurso do professor:

\section{Excerto 2}

Catiana: Eu vejo muito assim / é / como é que eu posso te dizer / eu vou tentar me expressar assim bem / eu vou ser bem sincera / é um / é um / é um trabalho contínuo que eu não vejo / eu pego essas crianças no quinto ano assim / bem / bem como se diz no contexto / a palavra / bem cru / são crianças que chegam no quinto ano que não sabem o que é parágrafo / que não utilizam / não sabem usar um dicionário pronto / não sabem / crianças de quinto ano que não utilizam um dicionário / abrir um dicionário pra eles é terrível / não são acostumados a pesquisa / nada / o mínimo / contagem de parágrafo / não sabem / a utilizar um texto / um autor Lentão eu faço todo esse tipo de trabalho então a gente tem que trabalhar direto / produção / produção / porque no quinto ano / 0 meu quinto ano eu faço direto esse trabalho / é leitura e produção / é leitura e produção / leitura e produção.

(Entrevista 1 post professora Catiana - Dia 13 de marco de 2013)

As vozes que permeiam o excerto são a de autor empírico, de professora, a voz de personagem "as crianças" e a voz social dada a expressão "bem cru" para referir-se ao conhecimento dos alunos. O excerto sinaliza para a ideia de que as modalizações 
pragmáticas "posso" e "tentar" e a modalização apreciativa "bem sincera" são introduzidas para expor as avaliações tecidas sobre as capacidades de linguagem dos alunos. A tensão pragmática novamente se instaura pela representação da professora sobre o nível de conhecimento dos alunos.

Os trechos sublinhados correspondem à figuração que o professor faz do seu agir, enquanto, no trecho em negrito, o agir que está sendo descrito/avaliado é o dos alunos. No caso da figura de ação experiência, esta é a figura de ação que mais está conectada ao repertório de saberes do professor. Saberes práticos, por assim, dizer, pois estão colocados como conclusões que o professor tira da sua história, das suas experiências e os recontextualiza, ao relatar aquela aula determinada. Dessa forma, faz uma espécie de ponte entre as experiências vividas anteriormente e aquele acontecimento, aquela aula em particular, reforçando ou não representações e conhecimentos prévios.

Para nós, esse tipo de ação de linguagem é caracterizador, isto é, deixa clara a dimensão formativa da figuração do agir. São conclusões praxiológicas que conectam o plano da experiência vivida nas práticas sociais concretas (no caso, o agir professoral), com o mundo das obras culturais e com o plano dos conhecimentos e representações individuais. Essas conexões, reforçadas ou reformuladas, passam a constituir o saber-fazer do professor (LEUROUIN, 2014) dentre outros aspectos identitários e gnosiológicos concernentes a sua profissão. Entre os saberes estão os do contexto, dos recursos e das capacidades de linguagem ao referir-se aos alunos. Também estão subjacentes os saberes sobre a metodologia, acerca da prática em sala de aula e referentes aos conteúdos ao mostrar que é preciso trabalhar conjuntamente a leitura e a produção para melhorar a escrita dos alunos.

No que concerne ao professor, a ontologia de uma conjunção do seu agir e do agir dos alunos, produzida pelas interações em sala de aula, é representada como um conjunto de «ações conjuntas», cuja alternância da figuração interna e externa é a característica principal. A convivência, no plano gnosiológico, desses dois conjuntos de interpretações enseja dupla ancoragem: Do ponto de vista da prática (ontologia), o agir do professor se caracteriza pela intervenção no agir de outrem (alunos). No plano interpretativo, a ação na aula de LM se elabora como alternância de figurações internas e externas em constante relação de codependencia complexa (motivacional de resultados etc.). 


\section{Considerações finais}

A característica principal do agir do professor é a de se desdobrar em microatividades cujo <<eixo de validade>> sociossubjetivo é o da negociação sobre o agir dos alunos. Paralelamente, o professor avalia e reconstitui esse agir com base no sucesso ou fracasso dos seus efeitos sobre o agir dos alunos. Percebemos, nos textos analisados, a bifurcação da rede de interpretações produzidas pelos professores, ora se referindo ao seu agir, ora se reportando ao agir dos alunos, ocasionando uma dupla ancoragem, tanto do ponto de vista ontológico (a ação é realizada pelo professor, mas sempre com uma expectativa sobre o agir do aluno), quanto gnosiológico (a interpretação do agir referente dá-se por meio de figuras de ação internas e externas). O agir profissional do professor é um agir sobre a ação de outro, cuja principal característica é a de desdobrar a sua ação em uma série de microatividades cuja matriz de referência sociossubjetiva é a da negociação sobre o agir dos alunos.

Os saberes subjacentes evidenciados centram-se em saberes sobre os recursos, a avaliação das capacidades de linguagem dos alunos, o conteúdo e a prática em sala de aula.. Conforme Bronckart (2001) exprime, o professor tenta "se entender para agir e agir para se entender" com seus alunos. Resta pois a questão: como apoiar o professor a reorganizar suas capacidades accionais, seus conhecimentos e seus modos de fazer com suporte na figuração que há no seu discurso? Parece-nos que a análise discurso do professor sobre a sua prática aponta para necessidades formativas específicas, todas ligadas à execução de um agir capaz de influenciar as representações e os modos de fazer dos alunos, assim como, garantir a adesão desses a um projeto de formação de usuários competentes da língua materna. Fica o desafio.

\section{Referências}

BRASIL. Ministério da Educação. Conselho Nacional de Educação/Câmara Superior de Educação. Diretrizes Curriculares Nacionais para a Formação de Professores da Educação Básica, em nível superior, curso de licenciatura, de graduação plena. Parecer: CNE/CP no oog de 8 mai. 2001. Disponível em: <http://portal.mec.gov.br/cne/arquivos/pdf/oog.pdf>. Acesso em: 10 jan. 2011. 
BRONCKART, J.-P. "Entrevista com Jean-Paul Bronckart, avec la collaboration d'Ecaterina Bulea, réalisé par Ermelinda Barricelli e Siderlene Muniz-Oliveira" - In : Revista L@el em (Dis-)Curso, vol. 3, no. 1, 2011.

Activité langagière, textes et discours. Pour un interactionisme socio-discursif, Paris, Delachaux et Niestlé (Traduction: (1999). Atividade de linguagem, textos e discursos. Por um interacionismo socio-discursivo, São Paulo, EDUC).1997.

Por que e como analisar o trabalho do professor. In: Atividade de linguagem, discurso e desenvolvimento humano, Campinas (Brasil): Mercado de Letras, 2004a, p. 203229 .

Pourquoi et comment analyser l'agir verbal et non verbal en situation de travail. In: Cahiers de la Section des Sciences de l'Éducation, Genève, n.103, 2004b.

Atividade de linguagem, discurso e desenvolvimento humano. MACHADO, A. R.; MATENCIO, M. L. M (orgs. e trad.). Campinas/SP: Mercado de Letras, 2006.

S'entendre pour agir et agir pour s'entendre. In J.-M. Baudouin \& J. Friedrich (Eds), Théories de l'action et éducation (pp. 133-154). Bruxelles: De Boeck.2001.

BRONCKART, J-P. Atividade de linguagem, textos e discursos: Por um interacionismo sóciodiscursivo. Trad. Anna Rachel Machado, Péricles Cunha. São Paulo: EDUC, 1999.

BULEA, E., LEURQUIN, E. \& CARNEIRO, F. "O agir do professor e as figuras de ação: por uma análise interacionista" - In : Bueno, L.; Lopes,M. e Cristovão, V. (orgs). Gêneros textuais e formação inicial : uma homenagem à Malu Matencio. Campinas, SP : Mercado de Letras, 2013.

BULEA, E. Linguagem e efeitos desenvolvimentais da interpretação da atividade [Langage et effets développementaux de l'interprétation de l'activité.], São Paulo : Mercado de letras, 2010.

BULEA, E.; BRONCKART, J.-P. "Les conditions d'exploitation de l'analyse des pratiques pour la formation des enseignants." - In : Linguarum Arena. Revista do Programa Doutoral em Didáctica de Línguas da Universidade do Porto, vol. 1, n²1, 2010, p. 43-6o.

BULEA, E. Le rôle de l'activité langagière dans les démarches d'analyse des pratiques à visée formative, Thèse de doctorat: Université de Genève, FPSE. 2007.

CAMILA, M. M. P. Representações do agir docente: análises de reconfigurações do agir no discurso do professor. 2011. Tese (Doutorado em Lingüística) - Universidade Federal do Ceará.

CARNEIRO, F. D. V. TransforAmar a prática educativa: instruir, formar, emancipar. In: $4^{\circ}$ Compartilhando: TransforAmar a prática educativa, 2014, Fortaleza. TransforAmar a Prática educativa: $4^{\circ}$ compartilhando. Fortaleza: Ipiranga, 2014. v. 2. p. 60-70. 
EUROPA. CONSEIL DE L'EUROPE. Portfolio européen pour les enseignants en langues en formation initiale. CENTRE EUROPÉEN POUR LES LANGUES VIVANTES (CELV). 2007. Disponivel em: http://archive.ecml.at/mtp2/publications/C3_Epostl_F_internet.pdf> Acesso em 10 abr. 2010.

EMPEYTA, S. F. Ecritures Soignantes : Agirs Et Discours En Situations De Soins.2010. VTLS. 25 Sep. $2015<$ http://archive-ouverte.unige.ch/unige:6003>.

FACCI, M. G. D. Valorização ou esvaziamento do trabalho do professor: um estudo críticocomparativo da teoria do professor reflexivo, do construtivismo e da psicologia vygotskiana. Campinas: Autores associados, 2011.

FRANCINETE, P. R. A. Cenas do estágio curricular supervisionado: análise e interpretação, discursivo-enunciativas de práticas dos professores em formação. 2013. Tese (Doutorado em Linguística) - Universidade Federal do Ceará.

HOFSTETTER R.; SCHNEUWLY, B. Savoirs en (trans)formation. Au cœur de l'enseignement et de la formation. In: (Org.).Savoirs en (trans)formation. Au cœur de l'enseignement et de la formation. Bruxelles: De Boeck, Coll. Raisons Éducatives, p. 7-40, 2009.

LEONTIEV, A. El desarrollo del psiquismo. Madrid: Akal.1983.

LEUROUIN, E. V. L. F. O espaço da leitura e da escrita em situação de ensino e aprendizagem de português língua estrangeira. Eutomia (Recife), v. 02, p. 68, 2014.

MACHADO, A.R. O diário de leituras: a introdução de um novo instrumento na escola. São Paulo: Martins Fontes, 1998.

MACHADO, A. R.; CRISTOVÃO, V. L. L. O agir do professor em documentos institucionais brasileiros para a formação inicial. In: CONGRESSO INTERNACIONAL EDUCAÇÃO E TRABALHO: Representações sociais, competências e trajectórias profissionais, 2005, Aveiro. Anais... Aveiro: Universidade de Aveiro, 2005.

SALES, F. F.; LIMA, L. C. As representações sociais do aluno de escola pública partilhadas por professores de língua inglesa que ensinam em escolas públicas e particulares de Teresina. Atos de pesquisa em educação - PPGE/ME FURB, v. 2, no 1, p. 106-122, jan./abr. 2007.

SAUSSURE, Ferdinand de. De l'essence double du langage, transcription diplomatique établie par Rudolf Engler d'après le manuscrit déposé à la Bibliothèque de Genève (1996). Texto! décembre 2004 -juin 2005 [en ligne]. Disponible sur: <http://www.revuetexto.net/Saussure/De_Saussure/Essence/Engler.html>.

SCHÖN, D. The Reflective Practitioner: How professionals think in action. London: Temple Smith, 1983. 
SCHNEUWLY, B. Retour aux savoirs: Le défi des didactiques dans une société en mutation. In: Colloque « Une éducation pour la Suisse du future » - Berne 21 avril 2010.

L'objet enseigné. In: DOLZ, J. Des objets enseignés em classe de français. Rennes Cedex: Presse Universitaire de Rennes, 2009, p. 17 - 28.

Vygotski, l'école et l'écriture. Genève: Cahiers de la section science de l'éducation Université de Genève, 2008.

STUTZ, L. Sequências didáticas, socialização de diários e autoconfrontação: instrumentos para a formação inicial de professores de inglês. 2012, 388 f. Tese (Doutorado em Estudos da Linguagem) - Universidade Estadual de Londrina, 2012.

REICHMANN, Carla Lynn. Práticas de letramento docente no estágio supervisionado de letras estrangeiras. Rev. Bras. Linguist. Apl., Belo Horizonte, v. 12, n. 4, p. 933-954, 2012. Disponivel em: <http://www.scielo.br/scielo.php?script=sci_arttext\&pid=S198463982012000400013\&lng=en\&nrm=iso>. Acesso em: 10 July 2013.

VANHULLE, S. Favoriser l'émergence du «je» professionnel en formation initiale: une étude de cas. Revue des sciences de l'éducation. V. 31, n. 1, p. 157-176, 2005.

\footnotetext{
' Lídia STUTZ

Professora do Departamento de Letras e do Programa de Pós-Graduação em Letras da UNICENTRO lidia.stutz@gmail.com

ii Fábio Delano Vidal CARNEIRO

Pesquisador da Universidade Federal do Ceará e professor titular da Faculdade Sete de Setembro fdvc13@gmail.com
} 